\title{
A Multi-dimensional Service Chain Ecosystem Model
}

\author{
Frédérique Biennier, Régis Aubry, and Youakim Badr \\ INSA-Lyon, LIESP, INSA de Lyon Bat Blaise Pascal \\ F-69621 Villeurbanne, France \\ \{frederique.biennier, regis.aubry, youakim.badr\} @insa-lyon. fr
}

\begin{abstract}
The globalised and moving economical environment leads enterprises to develop networked strategies. Such collaborative networks are by now often based on trusted and well known communities and require IT support agility and interoperability. The European Union promotes solutions to support and favor innovative business networks on the basis of an internet of services: these FP6 and FP7 projects results provide a consistent environment (including design, methods and developments related to Enterprise Service Bus (ESB) technology) to support technologically Business Service oriented organizations and the large-scale reinforcement of collaborative business and networked organization strategies. Nevertheless these works are mostly focused on an IT vision without taking into account business constraints. To overcome this limit, we propose a multi-dimensional service-chain ecosystem model, paying attention on service functional and non-functional properties description to support an efficient and consistent business service selection and composition process so that large-scale service based collaborative organization can emerge.
\end{abstract}

Keywords: Business Services, Modeling, Service Ecosystem, Process Maturity.

\section{Introduction}

Currently, the market is undergoing structural changes from mass customisation to increased interest in product and service management. Conversely, industries are shifting from labour-intensive jobs to the outsourcing of production in low-labour cost countries. Competition in overcrowded and existing industries is also moving to uncontested market spaces that make competition irrelevant. Such an economical context will favour in the coming years the emergence of an ecosystem of services. According to the Blue Ocean Strategy [5], demand is created rather than fought over. Services can allow firms to appropriate uncontested marketplace that creates and captures new demand while aligning the whole system of a firm's activities in pursuit of differentiation and low-cost. According to this strategy, product-service systems are built dynamically to anticipate consumer demand and will support new business opportunities and innovation.

In the most general sense, an ecosystem of services is a complex system of services, consisting of services and the relationships between them. This perceived assemblage of interrelated services comprises a unified whole to facilitate the flow of resources such as knowledge, competences and added-value. The integration of services when selling a product-service association increases the need for inter-firm 
collaborations and leads to the organization of industrial activities according to dynamic added-value networks instead of Porter's traditional value chain model [10].

In order to improve the enactment of an ecosystem of services, various services must identified by partners and published so that more complex services chain can be built, leading to a service chain organisation. Nevertheless, such collaborative organizations are limited as they require each partner to develop a consistent collaboration strategy. To overcome this drawback and provide extended business service communities, we propose to develop a service publication strategy requiring convenient selection and composition processes so that large scale service-oriented communities can emerge.

After describing globally the context associated to both product-service systems and the technological solutions, we propose our multi-dimensional service ecosystem model before setting the principles of a consistent Industrial-service bus.

\section{Context}

To fit the renewed globalised economical environment, enterprises, and mostly SMEs, have to develop new networked and collaborative strategies, focusing on their core business. The increased call for massively customised products also networked value creation (instead of the classical value chain vision). These collaborative organisations increase the call for interoperability at the technological, business and decisional levels.

- Focusing on the technological level, the FP6 and FP7 work programs have launched different project based on the Internet and service technology. Reference Architectures defined by IT professionals or administrative organisations such as TOGAF, FEAF, MODAF... promotes multi-layered architectures so that different tiers are used to decouple the data storage, the business rule implementation and the user interface. Coupled to SOA organisation and standards, these architectures increase the global interoperability level.

- At a conceptual layer, interoperability stakes are mostly related to business semantics (business data as well as business rules).

- At an organisational layer, [3] proposes a consistent decisional framework, paying attention to responsibility areas identification

The interoperability framework proposed by the ATHENA project [2] includes different dimensions (enterprise level, interoperability barriers...). This multi-dimensional framework can be used to identify a first interoperability taxonomy but it lacks of taking into account industrial strategies. This last point involves paying attention to the value-chain identified by the client, leading to a product service strategy to fit the best the customer needs. Product-service systems have been pointed out since the beginning of the 2000s [6]. Different organisation can be identified [11]:

- Product oriented Product-service systems: the physical product is owned by the consumer and services (mostly delivery services) are attached to the product itself 
O Use-oriented product Service System configuration: the consumer only buys the right to use the physical product

o Result-oriented Product-service system: the product is substituted by a service which is bought by the consumer. In this case, the physical product can not be easily identified.

These different models lead to a product-service taxonomy based on the product identification and ownership but they lack of taking into account the global product service supply-chain organisation. To overcome these limits, a global product-servicechain organisation taxonomy is required.

\section{Multi-dimensional Service Ecosystem Model}

We define a service ecosystem recursively either as a service-chain ecosystem which links a set of service ecosystems, or as a simple, stand-alone service. Services are mostly associated with "intangible assets" which require precise specifications so that the consumer can "recognise" the asset he or she receives in addition to adapted management strategy. Consequently, the traditional supply chain, manufacturing chain management and value models must be adapted [4] to take into account the intangible characteristics and various delivery channels. Delivery channels are direct when the consumer receives the service asset, and indirect when the consumer benefits from the service. When intangible service assets are concerned, services can either be delivered virtually through the internet; or when the service can be associated with a tangible asset, logistics are required to deliver the real asset.

\subsection{Multi-view Model Organisation}

Based on these constraints, we propose to analyse and model the service eco-system according to three different points of view:

○ Internal view: this includes different facets:

○ Product-Service competencies: This describes what the product and or service can be used for. As proposed in the Shostack model [7], these "competencies" can be related either to intangible and tangible assets in a product-service logic. The service competencies are related to a business-area ontology and pays attention on the production resources (machines, materials...), the produced product and / or service

o Service production system: this part is devoted to "non functional properties" description. It includes the service production process description, the production management strategy based on the Silvestro matrix [8], as well as monitoring and management information (including both key performance indicator collection and consolidation and process maturity control based on the CMMI for services classification [9].

- IT facet: This last facet includes service data description (in order to improve mediation processes), process description (based on BPMN) and security requirements. 
o Service Chain view: this view is related to the role a service can play in service chain assembly and represents the public aspect of the service model. It uses the service interface such as the service's competencies to select the convenient service to set an adapted service ecosystem. In this view, emphasis is placed on how global synergy can create added value for the global chain assembly. This model is described according to three dimensions taken with respect to the service internal view: the intangible/tangible axis, the production organisation strategy and process maturity. By such, service chain profiles can be set up and used in order to build a consistent service chain and support a trusted management organisation.

o Environmental view: this last view describes the service chain selection policy in terms of goals, service chain roles, strategic selection criteria, management criteria and environmental impact. The environmental view is related to the value perceived by consumers or other service providers. It can be associated to the prices the consumer pays for the different service chain components. In order to capture the client value-added point of view, we propose to use two elements, namely intangible/tangible characteristics and the direct/indirect delivery channel to describe the service asset. A third element is based on Maslow's pyramid of needs so that the service consumer goal can be described more precisely.

Gathering these different views leads us to build a global, multi-dimensional valueadded model. The perception of this model's taxonomy, regardless of its complexity, depends on best practices and pre-defined patterns. As a result, ecosystem evolution can be captured and adapt itself in a large, heterogeneous socio-economical and organisational context.

These collaborative and opened organizations make a heavy use of ICT, calling for information system agility and interoperability. Nevertheless, the underlying business-area oriented IT organization does not take into account the business process organization and can hardly support efficient traceability features as each business area is supported by an independent software environment and leads to inefficient information exchange, process organization and supervision..

Of course B2B and e-business tools (as e-market places for example) can be used to support web-based interactions between enterprises. Nevertheless, these webeconomy oriented collaborative frameworks are devoted to commercial relationships and do not integrate any industrial constraints nor business related knowledge. This can lead to inconsistent industrial collaborative organization, decreasing the global efficiency and increasing waste rate due to non value-added activities. To overcome these limits, we propose to add an industrial service layer on the traditional ESB organization so that industrial constraints can be taken into account.

\subsection{Industrial Service Bus Organisation}

To support the Service Ecosystem model, an adapted environment, paying attention on the Business and industrial semantics, is required. The Industrial Service Bus we propose couples a Semantic Enterprise Service Bus organisation (based on the ESB PETALS and its semantic SEMEUSE extension) and a Registry and Governance toolset to a dedicated industrial-service management level (see fig. 1). 


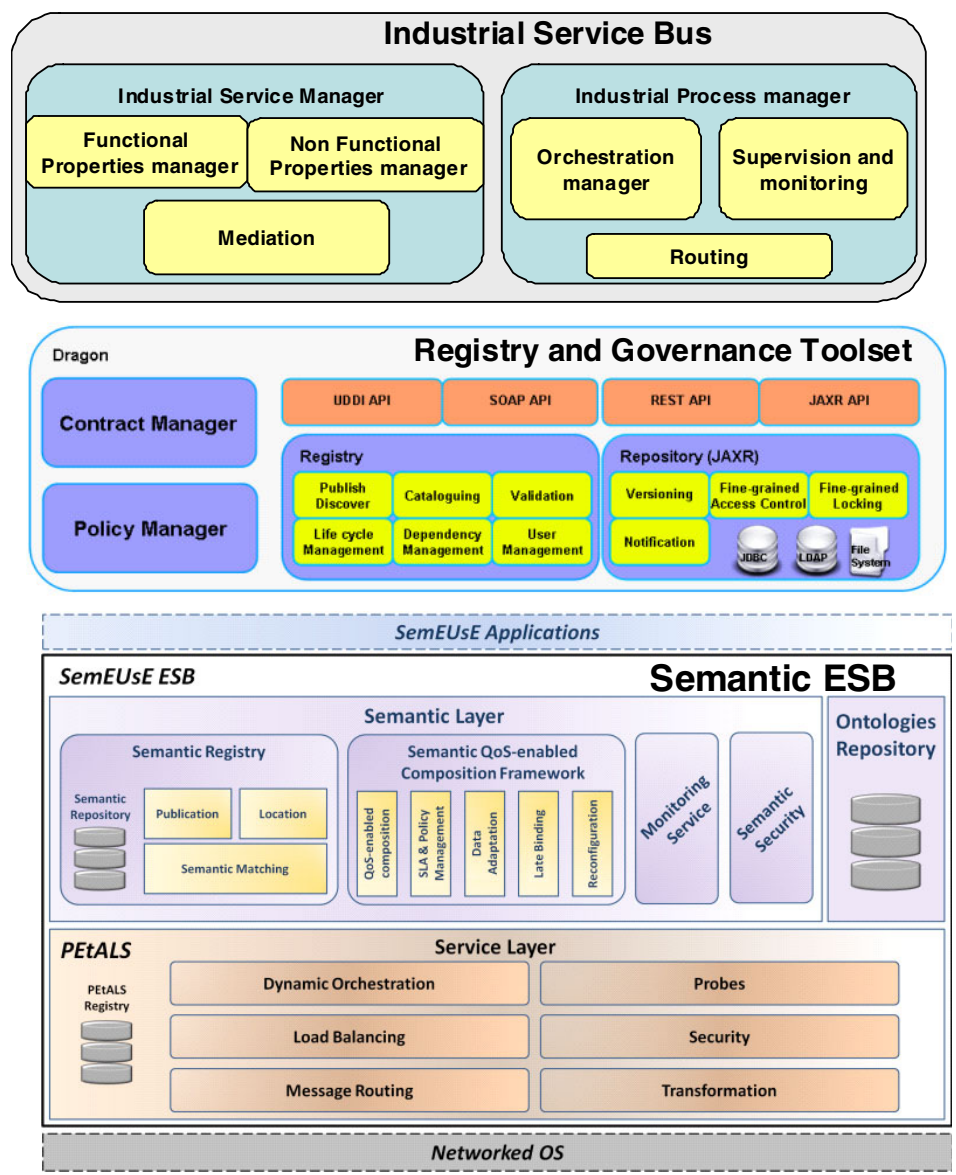

Fig. 1. Industrial Service Bus organisation

This Industrial service layer integrates different components:

- The Industrial Service manager includes 2 sub-parts

- Selection and composition: this module is the interface with the industrial service registry. It allows the organisation of the functional properties (based on the business area ontology) and of the non functional properties (based on the production, security and Industrial Quality of Service ontologies)

- Mediation: this block relies on a common ontology linking the different business areas concepts so that an efficient semantic and syntactic mediation can be set.

o The Industrial Process manager includes also 2 main components:

○ Choregraphy and orchestration: This component is in charge of the service combination so that a collaborative process can be built. It includes a high-level BPEL description turned into a concrete BPEL model transferred to the semantic ESB middleware 
- Supervision and governance: this component is in charge of transforming the industrial indicators defined previously in a consistent composition of monitored non-functional properties. This part is mostly devoted to the Dragon interface management

\subsection{Multi-dimensional Industrial Service Registry Organisation}

As said previously collaborative organisation based on the product / service ecosystem relies on an efficient product and / or service selection and composition to set a convenient service ecosystem fitting the customers needs. By now, these collaborative organisations gather partners belonging to a same trusted community. In order to allow large scale collaborative strategies, product and / or services should be published in industrial registries so that the potential partnerships are increased.

We propose to build the industrial registry on the existing semantic registry managed by the DRAGON and SemEUse projects. Each service is described according to 3 main dimensions:

- Product and / or service provider information: This part includes the partner administrative information, location information (in order to improve the delivery process). Coupled to social network toolsets, this part can implement trusted communities organisations.

o Product and / or service functional properties: This axis refers to the product and / or service "environmental" description. It includes 3 parts:

- Competencies description: This part is related to the business area ontology identification. It refers to the production machines and tools, material and product / service identification

- Production strategy description: This parts is used to take into account the production management strategy (to set consistent service chain),

- IT support characteristics: this part refers to the interoperability model developed by the ATHENA consortium so that the selection process can be "guided" to select partners supporting interoperable infrastructures.

○ Product and / or service non functional properties: This part includes:

- Security requirements: This part allows different security strategies depending on the trust level the product/service provider has on the current environment. These annotations refers to the perceived risks and are used Quality of Protection Agreements

- Quality requirements: This part is based on the CMMI classification. First defined in the software development context, the Capability Maturity Model Integration has been fruitfully adapted to other production contexts including service environment [9]. We use the different classification strategies as basic ontology entries so that the global quality can be evaluate. It includes 4 main classes: risk management (referring to contextual information to identify success / failure factors), requirement development (to identify the customisation parameters) configuration management (if the product / service can be tuned according to given patterns), Organizational Process Definition (referring to the way the production process is integrated in the global service chain). Each of these classes is evaluated 
according to 4 points of view: the ecosystem management strategy, the global, production process management, support functions and / or associated services and engineering activities (if required)

- Industrial Quality of service requirements: This Industrial Quality of Service ontology is organised according to $\mathrm{x}$ topics: mean cost, production delay, reporting facilities and the adaptation level. This last part is coupled to the supervision and governance module. This module orchestrates probes services to set continuous monitoring. As proposed in [1] each dimension is associated to a reference model (based on ontologies) used to support the service semantic description as WSDL annotations (see fig. 2). By this way both functional and static non functional properties can be used to select the product / service candidates to establish the ecosystem fitting the best the customers needs. Quality requirements and Industrial Quality of Service requirements are gathered to set manufacturing Service Level agreements so that the contractual part can also be generated "on the fly".

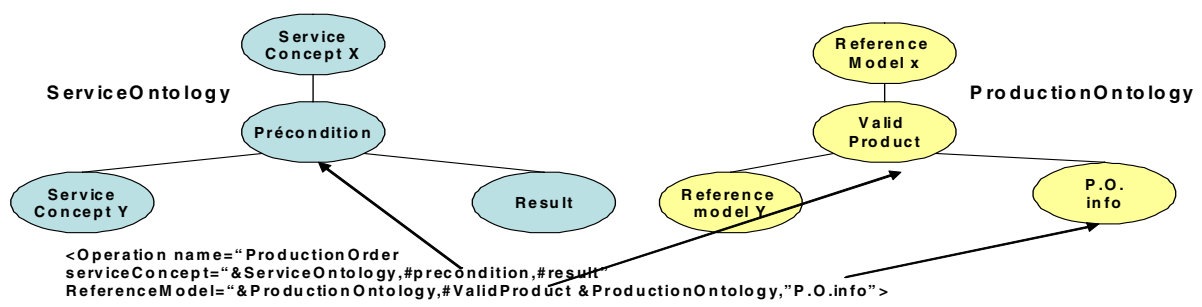

Fig. 2. Semantic annotation using YASA4WSDL

\section{Conclusion}

Due to increased customization in a globalized economy and to the development of "Service Oriented Products," enterprises have to adapt their organizational and business strategy, enhancing their own agility, reducing waste or non value-added activity and focusing on their core-business. Setting collaborative processes between enterprises and especially among SMEs is a promising approach to industrial competitiveness and is expected to generate substantial savings, expand market positions or develop new opportunities for the participants. To develop large-scale collaborative organization, we propose a product / service ecosystem taxonomy so that the different components of the ecosystem can be identified and selected. This leads us to define an "industrial service bus" layer. Based on a semantic ESB, this project is currently under development.

Acknowledgments. This work is partly supported by the Rhone-Alpes Area council via the Cluster GOSPI Sim-SyProd project and by the ANR organisation via the SemEUse project under ANR 20707TechLog018 grant. 


\section{References}

1. Chabeb, Y., Tata, S.: Yet Another Semantic Annotation for WSDL. In: IADIS International Conference WWW/Internet 2008, pp. 437-441 (2008)

2. Daclin, N., Chen, D., Vallespir, B.: Decisional Interoperability: Concepts And Formalisation. In: Proceedings of Network-Centric Collaboration and Supporting Frameworks, PRO-VE 2006. IFIP, vol. 224, pp. 297-304. Springer, Heidelberg (2006)

3. Daclin, N., Chapurlat, V.: Evaluation de l'interopérabilité organisationnelles et manageriale des systèmes industriels: Le projet CARIONER, http://www.supdecomontpellier.com/fileadmin/cerom/docs_telechargement/ MTO_2008/Daclin_Chapurlat_MTO_2008.pdf

4. Ellram, L.M., Tate, W.L., Billington, C.: Services Supply Management: The Next Frontier for Improved Organisational Performance. California Management Review 49(4), 44-66 (2007)

5. Kim, W.C., Mauborgne, R.: Blue Ocean Strategy. Harvard Business Review, 76-84 (October 2004)

6. Mont, O.: Product-service systems: panacea or myth? PhD Dissertation. Lund University (reference IIIEE2004.1) (2004)

7. Shostack, L.: Breaking Free from Product Marketing. Journal of Marketing 41 (1977)

8. Silvestro, R., Fitzgerald, L., Johnston, R., Voss, C.: Towards a Classification of Service Processes. International Journal of Service Industry Management 3(3), 62-75 (1992)

9. Software Engineering Institute: CMMI for Services, version 1.2. Carnegie Mellon University Technical Report (February 2009), http: / /www. sei.cmu.edu/ publications/documents/09. reports/09tr001.html

10. Tekes, S.: Value Networks in Construction 2003-2007. Sara Technology Programme, http: / / www. tekes.fi/english/programmes/sara

11. Yang, X., Moore, P., Pu, J.S., Wong, C.B.: A practical methodology for realizing product service systems for consumer products. Computers \& Industrial Engineering 56, 224-235 (2009) 